\title{
Circulating calcium levels and the risk of type 2 diabetes: a systematic review and meta-analysis
}

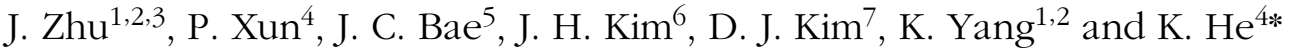 \\ ${ }^{1}$ Department of Clinical Nutrition, Xin Hua Hospital Affiliated to Shanghai Jiao Tong University School of Medicine, Shanghai \\ 200092, People's Republic of China \\ ${ }^{2}$ Department of Nutrition, Shanghai Jiao Tong University School of Medicine, Shanghai 200025, People's Republic of China \\ ${ }^{3}$ Nutrition and Foods Program, School of Family and Consumer Sciences, Texas State University, San Marcos, TX 78666, USA \\ ${ }^{4}$ Department of Epidemiology and Biostatistics, School of Public Health-Bloomington, Indiana University, Bloomington, IN \\ 47405, USA \\ ${ }^{5}$ Department of Internal Medicine, Samsung Changwon Hospital, Sungkyunkwan University School of Medicine, Changwon \\ 630-723, Republic of Korea \\ ${ }^{6}$ Department of Medicine, Samsung Medical Center, Sungkyunkwan University School of Medicine, Seoul O6351, Republic of \\ Korea \\ ${ }^{7}$ Department of Endocrinology and Metabolism, Ajou University School of Medicine, Suwon 443-380, Republic of Korea
}

(Submitted 17 January 2019 - Final revision received 11 April 2019 - Accepted 25 April 2019)

\begin{abstract}
Abnormal Ca homeostasis has been associated with impaired glucose metabolism. However, the epidemiological evidence is controversial. We aimed to assess the association between circulating Ca levels and the risk of type 2 diabetes mellitus (T2DM) or abnormal glucose homeostasis through conducting a systematic review and meta-analysis. Eligible studies were identified by searching electronic database (PubMed, Embase and Google Scholar) and related references with de novo results from primary studies up to December 2018. A random-effects meta-analysis was performed to estimate the weighted relative risks (RR) and 95\% CI for the associations. The search yielded twenty eligible publications with eight cohort studies identified for the meta-analysis, which included a total of 89165 participants. Comparing the highest with the lowest category of albumin-adjusted serum Ca, the pooled RR was 1.14 (95\% CI 1.05, 1.24) for T2DM ( $n 51489)$. Similarly, serum total Ca was associated with incident T2DM (RR 1.25; $95 \%$ CI 1·10, 1.42) ( $n$ 64 502). Additionally, the adjusted RR for 1 mg/dl increments in albumin-adjusted serum Ca or serum total Ca levels was 1.16 (95\% CI 1.07, 1.27) and 1.19 (95\% CI 1·11, 1.28), respectively. The observed associations remained with the inclusion of a cohort study with ionised $\mathrm{Ca}$ as the exposure. However, data pooled from neither case-control $(n 4)$ nor cross-sectional $(n 8)$ studies manifested a significant correlation between circulating $\mathrm{Ca}$ and glucose homeostasis. In conclusion, accumulated data from the cohort studies suggest that higher circulating Ca levels are associated with an augmented risk of T2DM.
\end{abstract}

Key words: Blood calcium: Serum calcium: Diabetes: Insulin: Glucose

Type 2 diabetes mellitus (T2DM), a major metabolic disorder characterised by hyperglycaemia, is associated with an increased risk of multiple chronic conditions ${ }^{(1,2)}$, such as $\mathrm{CVD}^{(3)}$ and nephropathy ${ }^{(4,5)}$. T2DM has been recognised as a leading cause of morbidity and mortality ${ }^{(1,6)}$.

$\mathrm{Ca}$, an essential mineral, exerts a wide range of biological functions, including bone and tooth mineralisation, blood coagulation, muscle contraction, nerve impulse transmission and cellular signalling transduction ${ }^{(4,6-9)}$. Additionally, Ca plays a pivotal role in insulin secretion and glucose homeostasis $(4,10,11)$. Glucose-dependent insulin secretion is a Ca-regulated process, which depends on intracellular Ca concentration in pancreatic $\beta$-cells ${ }^{(10,12)}$. Moreover, increased cytosolic $\mathrm{Ca}$ also affects glucose uptake in the myocyte ${ }^{(10,13,14)}$. Consequently, abnormal Ca homeostasis could potentially be involved with defects in insulin action and disorders in glucose homeostasis, contributing to T2DM development ${ }^{(4,10,11,15,16)}$.

Findings from epidemiological studies are inconsistent. Some observational studies have indicated that increased serum $\mathrm{Ca}$ concentration may be directly associated with the risk of developing $\mathrm{T} 2 \mathrm{DM}^{(3,4,6,7,17,18-21)}$, whereas others reported the null correlation between circulating $\mathrm{Ca}$ and prevalent $\mathrm{T}_{2} \mathrm{DM}^{(7,10,22)}$.

Abbreviations: NOS, Newcastle-Ottawa Scale; PTH, parathyroid hormone; RR, relative risk; T2DM, type 2 diabetes mellitus.

* Corresponding author: K. He, email kahe@indiana.edu 
Also, it has been observed that elevated serum Ca levels were related to insulin resistance ${ }^{(4,20,21)}$, reduced insulin sensitivity $^{(4,18,23,24)}$ and impaired glucose tolerance ${ }^{(4,16,17,23,24)}$, but not a decrease in insulin secretion ${ }^{(4,23,24)}$. These contradictory results may be partially attributable to diverse Ca assessments, for example, total serum $\mathrm{Ca}$ and albumin-adjusted serum $\mathrm{Ca}$, which are different biomarkers of $\mathrm{Ca}$ status ${ }^{(10,23)}$. Because approximate $40 \%$ of $\mathrm{Ca}$ in the serum is bound to albumin $^{(8)}$, it is vital to know the serum albumin level when evaluating the total serum Ca. Moreover, circulating Ca homeostasis is exquisitely regulated by multiple negative feedback loops which involve several integrated hormonal responses and target organs $^{(8)}$. Thus, each of these components may mediate the possible Ca-related risk of diabetes. Interestingly, two double-blind, placebo-controlled, randomised clinical trials reported non-significant effects of Ca supplementation on insulin resistance in obese adults ${ }^{(25)}$, as well as insulin secretion, insulin sensitivity and glycaemia in adults at risk of $\mathrm{T}_{2} \mathrm{DM}^{(26)}$. Of note, these studies have relatively short follow-up periods, insufficient numbers of participants and heterogeneous characteristics between populations $^{(25,26)}$

One early meta-analysis ${ }^{(9)}$ was conducted by Sing et al. based only on four cohort studies ${ }^{(3,4,9,17)}$, which reported a positive association of both serum total $\mathrm{Ca}$ and albumin-adjusted Ca with risk of diabetes. Since then, four additional cohort studies $^{(6,10,22,27)}$ with larger sample sizes have been published. Moreover, the linear association between circulating Ca levels and the T2DM risk has not been investigated.

Therefore, in the present study, we aimed to quantitatively assess the overall association between circulating Ca levels and the risk of T2DM or abnormal glucose homeostasis by performing an up-to-date systematic review and meta-analysis.

\section{Methods}

The present study was conducted according to the guidelines of Meta-analysis of Observational Studies in Epidemiology (MOOSE) $)^{(28)}$. The present study was registered with the International Prospective Register of Systematic Reviews (PROSPERO) (https://www.crd.york.ac.uk/PROSPERO/) with the registration number CRD 42018092835.

\section{Study search strategy}

We performed a systematic search of published studies in English in PubMed from inception to December 2018 using the terms 'calcium or serum calcium or blood calcium', 'diabetes or insulin resistance or impaired glucose tolerance or impaired fasting glucose', 'epidemiological studies', 'cohort/prospective longitudinal/follow-up/cross-sectional/case-control studies' and 'survival analysis or proportional hazard model or hazard ratio Cox or hazards ratio or odds ratio'. In addition, we searched Embase, Google Scholar and reference lists of narrative and systematic reviews to identify missing studies. Importantly, to standardise results specifically for this meta-analysis and to obtain additional information, we requested de novo data from two original studies ${ }^{(22,27)}$.

\section{Selection criteria}

Studies were considered for inclusion if they met the following criteria: (a) published in English; (b) had a cohort, case-control or cross-sectional design; (c) provided the exposure information of total serum $\mathrm{Ca}$, albumin-adjusted serum $\mathrm{Ca}$ or serum ionised $\mathrm{Ca}$ and (d) had a relative risk (RR), hazard ratio (HR) or OR with $95 \%$ CI for T2DM in relation to Ca exposure or a correlation coefficient between $\mathrm{Ca}$ exposure and T2DM related variables (e.g. fasting glucose, fasting insulin, insulin sensitivity and insulin resistance), or such information could be derived from the published results.

\section{Data extraction}

Two investigators (J. Z. and P. C. X.) reviewed all relevant literature and assessed the eligibility of each study independently. Discrepancies were resolved with consensus reached by group discussion. From each retrieved study, the following information was extracted: author name, year of publication, study region, total number of participants and events (or total number of cases and controls), proportion of males, age of participants, exposure evaluation method, exposure classification, adjusted variables and HR, RR or OR estimates with corresponding 95\% CI for all corresponding Ca exposure categories and/or for continuous exposure, compared with the lowest exposure group. OR reported in a cohort study ${ }^{(17)}$ was transformed to RR by adopting the following formula: $\mathrm{OR}=\left(\left(1-P_{0}\right) \times \mathrm{RR} /\left(1-\mathrm{RR} \times P_{0}\right)\right)$, where $P_{0}$ is the incidence rate in the reference group, according to the published methods ${ }^{(9)}$.

\section{Quality assessment}

The Newcastle-Ottawa Scale (NOS) system $^{(29)}$ was employed to evaluate the quality of each selected cohort study or casecontrol study. The NOS system has a maximum score of nine points. Studies with a sum score of $0-4,5-7$ and $8-9$ were considered as low, moderate and high quality, respectively. Also, the original version of the NOS system was modified for assessing the quality of the included cross-sectional studies for the systematic review based on the existing literature ${ }^{(30-32)}$. The modified NOS system has a maximum score of eight points. Studies with a sum score of $0-4,5-7$ and 8 were considered as low, moderate and high quality, respectively. Two co-authors (J. Z. and P. C. X.) independently conducted the quality assessment. Any unconformity was resolved with consensus reached by group discussion with the involvement of a third investigator.

\section{Statistical analysis}

We pooled the cohort studies' data for each outcome of interest using a random-effects model in Stata 13.0 (STATA Corp). $P$ values $\leq 0.05$ were considered statistically significant if not otherwise specified. For the comparisons, we used the multivariable-adjusted associations (RR) for the highest $v$. lowest category of albumin-adjusted serum $\mathrm{Ca}$ or total Ca levels, and for the linear associations, we used standardised Ca levels with $1 \mathrm{mg} / \mathrm{dl}$ increments. Because of an insufficient number of studies measuring ionised $\mathrm{Ca}$, we did not pool the data separately for this subgroup. Heterogeneity was estimated quantitatively using $I^{2}$ 


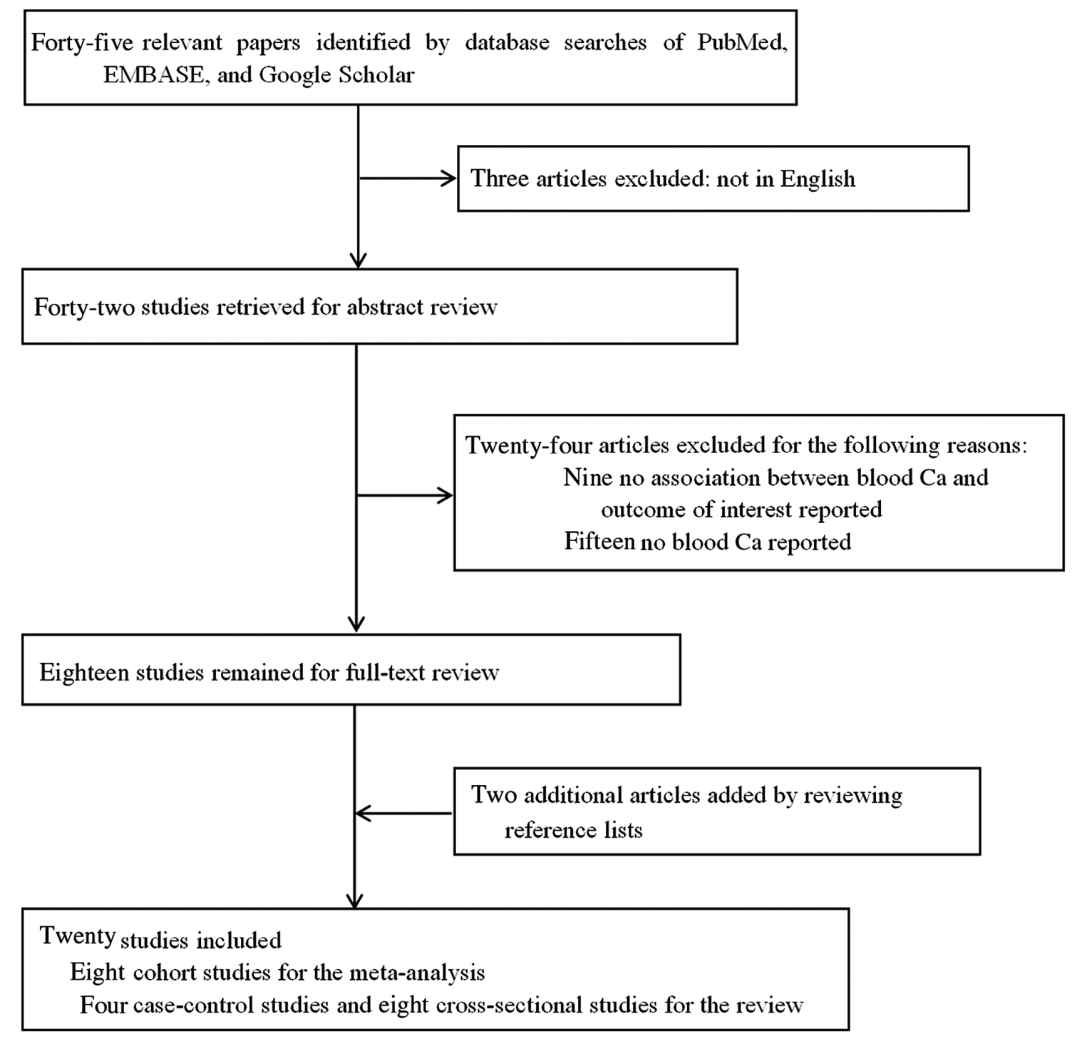

Fig. 1. Flow chart of study selection.

and tested by Cochran's $Q$-test. An $I^{2}$ value of $>75,51-75,26-50$ or $0-25 \%$ corresponds to high, moderate, low or very low heterogeneity, respectively. We evaluated publication bias through both Egger's asymmetry test and Begg's non-parametric test with the $\alpha$ level set as $0 \cdot 10$. The Duval and Tweedie nonparametric 'trim and fill' method was adopted, if publication bias existed $^{(33)}$.

We also conducted sensitivity analyses to assess the effect of replacing a random-effects model with a fixed-effects model and the influence of an individual study on the overall association by excluding one study each time from the analysis. We also evaluated the impact of one study measuring ionised $\mathrm{Ca}$ on the overall association by combining it with other studies.

\section{Results}

\section{Literature search}

The literature selection process is shown in Fig. 1. A total of forty-five related articles were retrieved from PubMed, Embase and Google Scholar. Of these, three articles were excluded since they were not issued in English; nine publications were further excluded because they did not associate blood $\mathrm{Ca}$ with an outcome of interest and additional fifteen articles were excluded because they did not report blood $\mathrm{Ca}$ as either a categorical variable or a continuous variable on the original scale. Furthermore, we also identified two articles by searching the reference lists of relevant publications. Thus, the search revealed eight cohort studies ${ }^{(3,4,6,9,10,17,22,27)}$ for the meta-analysis and another twelve eligible studies (four case-control studies ${ }^{(7,18,34,35)}$ and eight cross-sectional studies $\left.^{(19-21,23,24,36-38)}\right)$ for the systematic review.

\section{Study characteristics}

The information from the eligible studies was extracted (Tables 1-3). The total number of participants of all the included studies was 89165 (48.6\% males). For eight cohort studies $^{(3,4,6,9,10,17,22,27)}$, there were 80359 individuals $(49 \cdot 9 \%$ males) with 6447 incidents of diabetes. For four case-control studies $^{(7,18,34,35)}$, there were 858 individuals (35.9\% males) with 324 diabetes cases and 534 controls. For eight cross-sectional studies $^{(19-21,23,24,36-38)}$, there were 7948 participants $(37 \cdot 2 \%$ males) including 740 diabetes cases. The mean age of participants across primary studies was from $25 \cdot 7$ to 80 years.

Regarding the quality of the included eight cohort studies $^{(3,4,6,9,10,17,22,27)}$, six studies $(3,4,6,17,22,27)$ were assessed as high quality and two studies ${ }^{(9,10)}$ as moderate quality (online Supplementary Table S1). Of the included four case-control studies $^{(7,18,34,35)}$, two studies ${ }^{(18,34)}$ were assessed as moderate quality and two studies ${ }^{(7,35)}$ as low quality. For the included eight cross-sectional studies ${ }^{(19-21,23,24,36-38)}$, two studies ${ }^{(19,23)}$ were assessed as high quality and six studies ${ }^{(20,21,24,36-38)}$ as moderate quality.

\section{Meta-analysis of the cohort studies}

A significant association between albumin-adjusted serum Ca levels and T2DM incidence was found (RR 1.14; $95 \% \mathrm{CI}$ 
Circulating calcium levels and diabetes

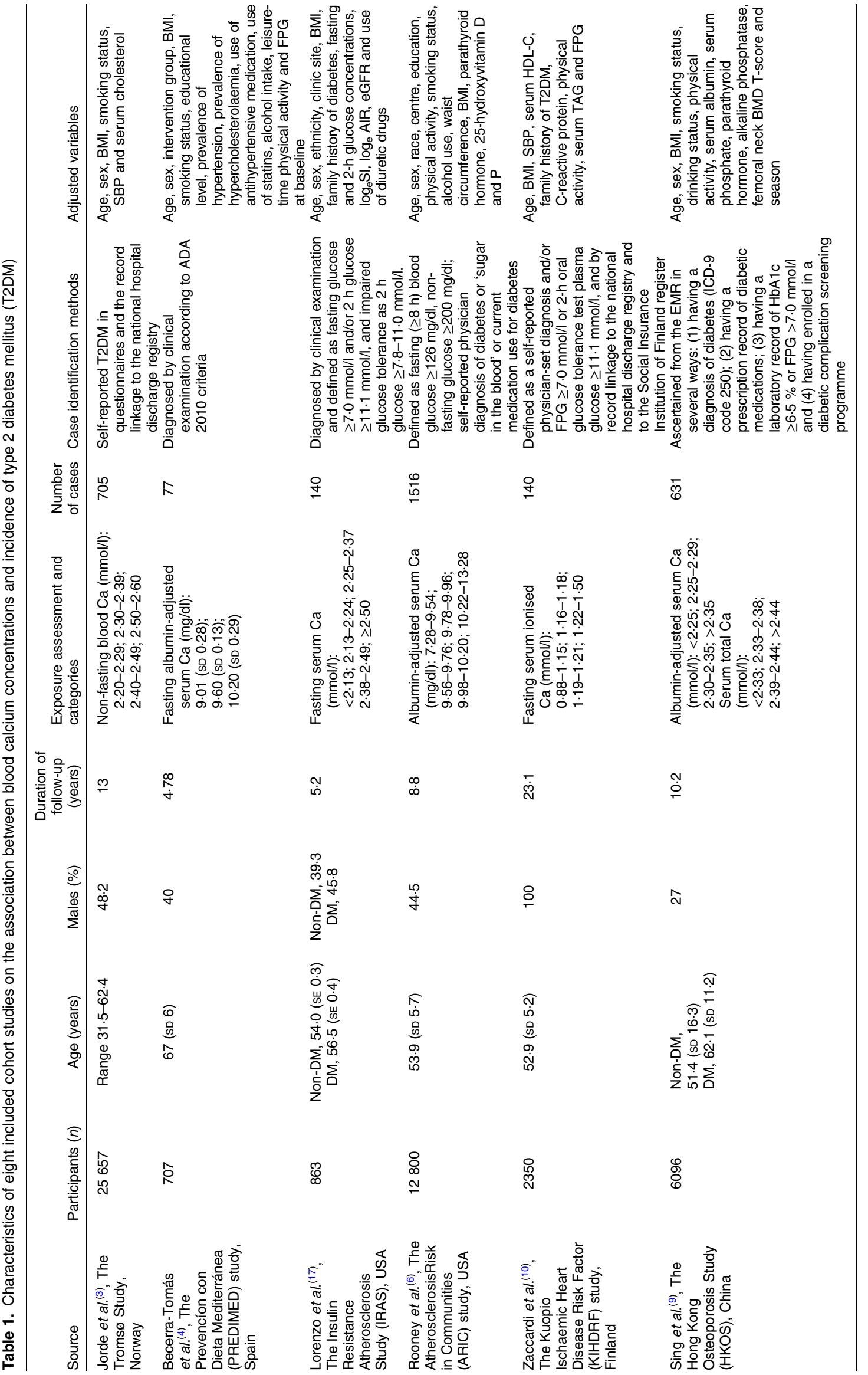


1.05, 1.24) (Fig. 2), comparing the highest with the lowest Ca levels based on available data from five cohort studies ${ }^{(4,6,9,22,27)}$. Neither heterogeneity $\left(I^{2}=0 \cdot 0 \%, P=0.550\right)$ nor publication bias (Egger's test: $P=0.631$; Begg's test: $P=0.462$ ) existed. Consistently, a significant linear association was found (RR 1.16; $95 \%$ CI 1.07, 1.27) with $1 \mathrm{mg} / \mathrm{dl}$ increments in albumin-adjusted serum Ca levels. Low heterogeneity $\left(I^{2}=33.8 \%\right.$, $P=0 \cdot 183$ ) was observed, but no publication bias (Egger's test: $P=0 \cdot 104$; Begg's test: $P=0 \cdot 452$ ) was evidenced. When adding the cohort study with ionised $\mathrm{Ca}$ as the exposure ${ }^{(10)}$, the aforementioned results of pooled RR remained (the highest $v$. the lowest: 1.13 (95\% CI 1.04, 1.22); per $1 \mathrm{mg} / \mathrm{dl}$ increment: $1 \cdot 16$ (95\% CI 1.06, 1.27)).

Similar results (Fig. 3) were found when the pooled analysis was restricted to studies ${ }^{(3,9,17,22,27)}$ that measured serum total Ca (RR 1.25; $95 \%$ CI 1.10, 1.42), comparing the highest with the lowest serum total Ca levels. However, low heterogeneity $\left(I^{2}=33.3 \%, P=0.199\right)$ and potential publication bias (Egger's test: $P=0.008$; Begg's test: $P=0 \cdot 027$ ) were observed. We then used the Duval and Tweedie non-parametric 'trim and fill' method and observed the overall RR was 1.21 (95\% CI 1.06, 1.38). A significant linear association was also found (RR 1.19 (95\% CI $1 \cdot 11,128)$ with $1 \mathrm{mg} / \mathrm{dl}$ increments in serum total Ca levels). No heterogeneity $\left(I^{2}=0 \%, P=0 \cdot 694\right)$ was observed, but potential publication bias (Egger's test: $P=0.031$; Begg's test: $P=0.221$ ) was evidenced. After using the Duval and Tweedie non-parametric 'trim and fill' method, we observed the overall RR was 1.18 (95\% CI 1.10, 1.26). When further including the study that assayed ionised $\mathrm{Ca}^{(10)}$, the results of pooled RR persisted (the highest $v$. the lowest: $1.21(95 \% \mathrm{CI}$ $1.06,1.39)$ and 1.19 (95\% CI $1.11,1.27)$ with $1 \mathrm{mg} / \mathrm{dl}$ increments).

The sensitivity analyses revealed that replacing the randomeffects model with a fixed-effects model or any single study did not appreciably influence the pooled results or conclusions (online Supplementary Tables S4-S7).

\section{Systematic review of the case-control and cross-sectional} studies

The included case-control studies reported inconsistent results on the association between Ca homeostasis and diabetic risk. Higher serum total $\mathrm{Ca}$ levels ${ }^{(7)}$ or higher plasma Ca levels ${ }^{(18)}$ were reported in the middle-aged and elderly diabetic patients. Contrarily, normal serum total $\mathrm{Ca}^{(34)}$ and ionised $\mathrm{Ca}$ levels ${ }^{(7,34)}$ were observed, respectively, in the middle-aged and elderly diabetic patients, and decreased serum ionised Ca concentrations ${ }^{(35)}$ were also observed in the young diabetic patients, respectively, compared with the non-diabetic individuals (Table 2).

The included cross-sectional studies reported that serum Ca was directly correlated to glucose intolerance ${ }^{(21,23,36)}$, insulin resistance ${ }^{(21)}$, impaired glucose metabolism ${ }^{(20)}$, early phase insulin secretion $^{(37)}$ and diabetes ${ }^{(19,38)}$ mainly in middle-aged and elderly individuals. However, serum Ca was found inversely correlated to $\beta$-cell function in women ${ }^{(21)}$ and insulin sensitivity in older men ${ }^{(24)}$ (Table 3). 
Circulating calcium levels and diabetes

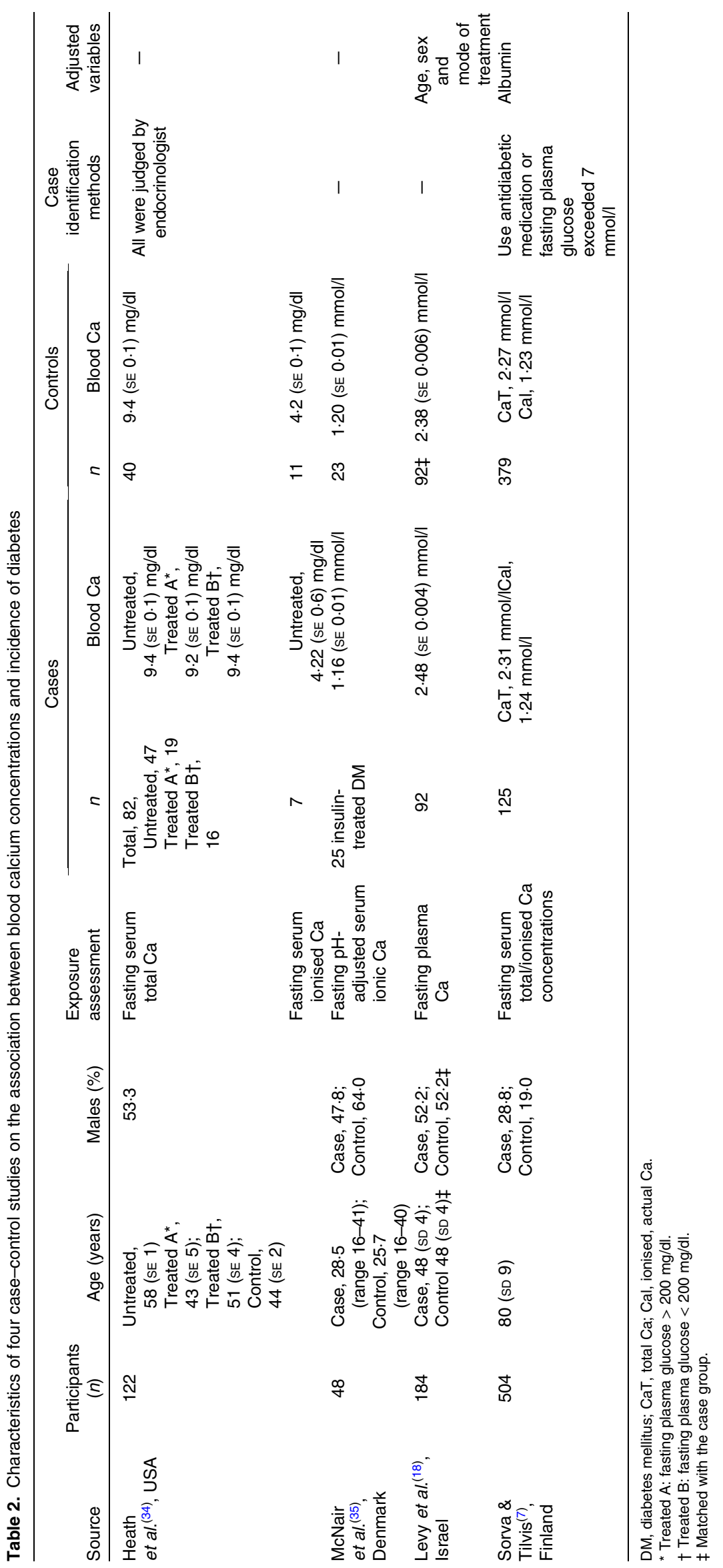




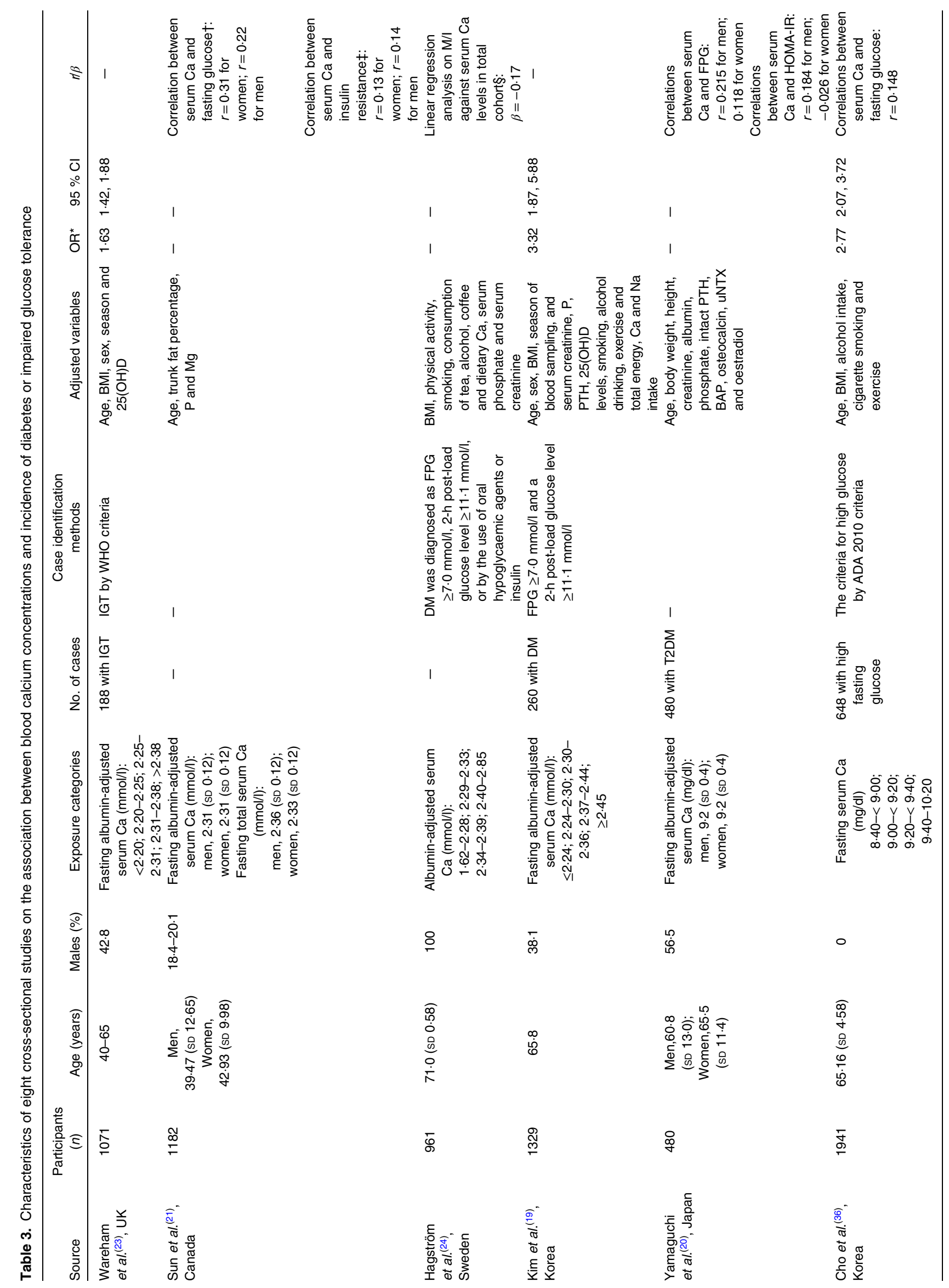




\section{Discussion}

The accumulated evidence from the cohort studies suggests that either albumin-adjusted serum Ca or serum total Ca was directly associated with T2DM risk, though data from case-control and cross-sectional studies were inconsistent and inconclusive. The present study provided updated and robust data to the literature by including additional and de novo results from a few newly published large cohort studies. Also, the present study investigated both categorical and linear associations between circulating $\mathrm{Ca}$ and T2DM incidence, which strengthened our conclusion.

The results in case-control and cross-sectional studies were not consistent, which may be partially explained by the different $\mathrm{Ca}$ measurements, such as total serum, albumin-corrected serum, serum ionised or plasma levels or heterogeneous study populations with various outcomes.

The results of the present study are inconsistent with findings from studies on dietary Ca intake and the T2DM risk ${ }^{(22,39-42)}$. One possible explanation is that dietary estimation and blood $\mathrm{Ca}$ are different assessments, which are subject to different measurement errors. Another explanation is that the dietary $\mathrm{Ca}$ and diabetes association may be confounded by Mg intake, which is highly correlated with $\mathrm{Ca}$ intake and associated with diabetes risk $^{(43)}$. Moreover, circulating $\mathrm{Ca}$ concentrations could reflect not only the exogenous $\mathrm{Ca}$ intake but also the endogenous capability of maintaining homeostasis ${ }^{(22)}$, which is tightly regulated by multiple negative feedback loops involving several target organs and hormones ${ }^{(3,6,8,22)}$. Ca intake may lead to an elevation of serum $\mathrm{Ca}$ that activates the Ca-sensing receptor $(\mathrm{CaR})$ in the parathyroid glands to reduce parathyroid hormone (PTH) secretion ${ }^{(8)}$. The reduced PTH inactivates the PTH receptor (PTHR) in kidney to decrease tubular Ca reabsorption, and PTHR in bone to decrease net bone Ca resorption ${ }^{(8)}$. The reduced PTH also results in a decreased secretion of 1,25 dihydroxyvitamin $\mathrm{D}\left(1,25(\mathrm{OH})_{2} \mathrm{D}\right)$, which inactivates the vitamin $\mathrm{D}$ receptor in intestine to reduce $\mathrm{Ca}$ absorption, in the parathyroid glands to augment PTH secretion and in bone to reduce $\mathrm{Ca}$ resorption ${ }^{(8)}$. The rise in serum Ca may also activate the $\mathrm{CaR}$ in kidney to decrease $\mathrm{Ca}$ reabsorption ${ }^{(8)}$. When a decrease in serum $\mathrm{Ca}$ occurs, this integrated hormonal response is reversed with serum $\mathrm{Ca}$ increased, which helps to maintain total serum Ca levels within a physiological range of approximately $10 \%{ }^{(8)}$. However, emerging evidence showed that hormones (such as PTH, 1,25(OH) 2 D) that participate in this complex homeostatic system have themselves been related to diabetes $^{(44,45)}$. Thus, abnormalities of these pivotal physiological factors may affect the Ca-diabetes association, which warrants further investigation.

The potential mechanisms underlying the role of circulating $\mathrm{Ca}$ in T2DM incidence remain unclear. However, growing evidence implies that $\mathrm{Ca}$ may mediate insulin secretion via activation of the $\mathrm{CaR}^{(46,47)}$, which is wildly expressed in tissues, such as pancreatic islets of Langerhans ${ }^{(46)}$. Glucose-dependent insulin secretion from the pancreatic $\beta$-cells is a Ca-regulated process $^{(11,12,48)}$, which requires the influx of $\mathrm{Ca}$ through voltage-gated $\mathrm{Ca}$ channels to the secretory granules in $\beta$-cells ${ }^{(49-51)}$. Thus, high $\mathrm{Ca}$ concentration may induce $\beta$-cell dysfunction $^{(21)}$. Moreover, abnormal Ca status impacts insulin 


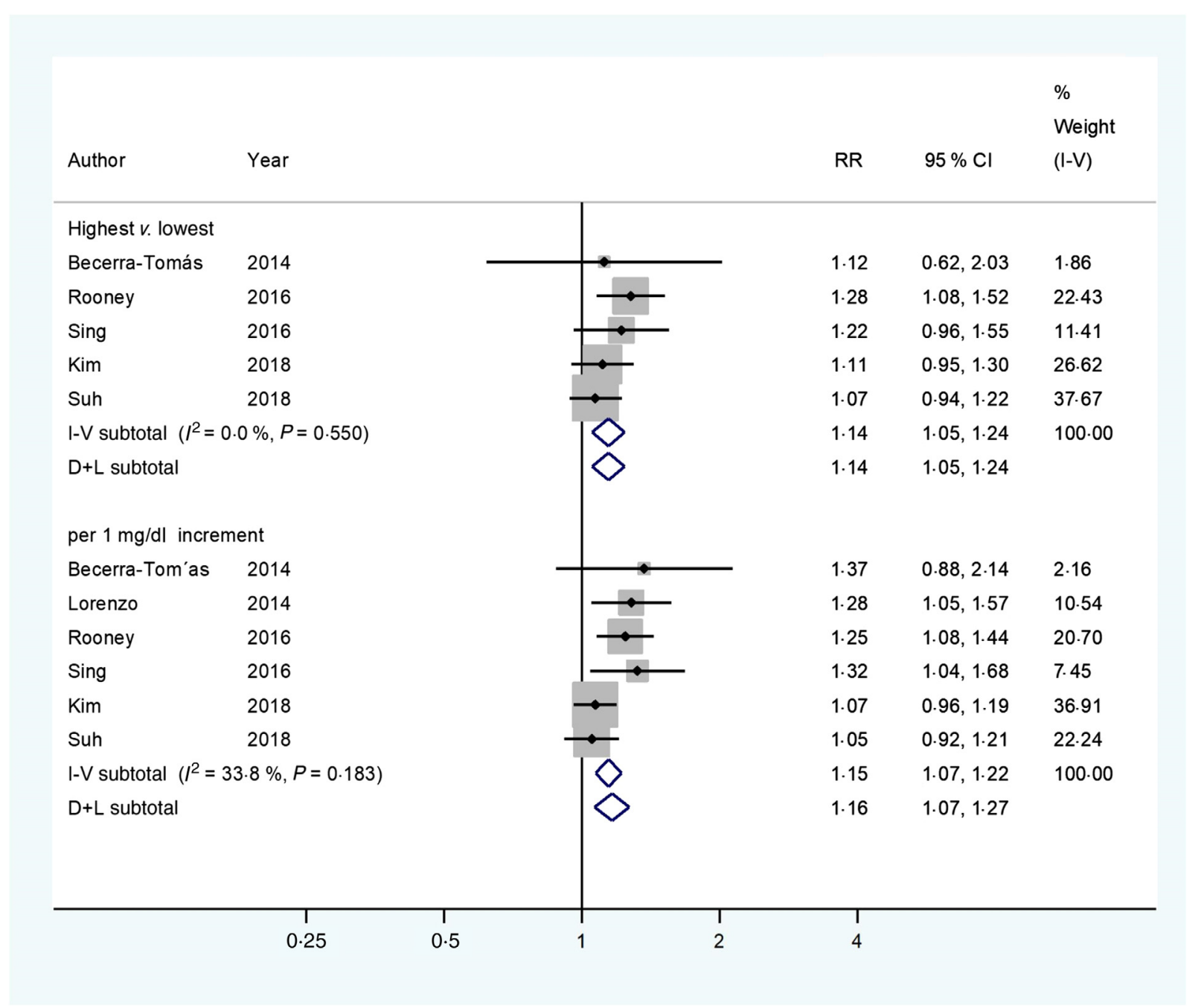

Fig. 2. Multivariable-adjusted relative risks (RR) ( $\bullet$ ) and $95 \%$ confidence intervals ( - ) of type 2 diabetes mellitus (T2DM) in relation to albumin-adjusted serum calcium levels. The summary assessments $(\diamond)$ were obtained by adopting a random-effects model. Values are adjusted RR comparing the highest with the lowest category levels or per $1 \mathrm{mg} / \mathrm{dl}$ increase in albumin-adjusted serum calcium. The size of the shaded square is proportional to the weight of each study. We requested de novo data from the authors of Kim et al. ${ }^{(22)}$ and Suh et al. ${ }^{(27)}$, respectively.

sensitivity and glucose transport in adipocytes and skeletal muscle ${ }^{(14,52,53)}$ through regulating GLUT4 expression, which is a passive transporter necessary for glucose uptake in peripheral tissues $^{(13,14)}$. Chronic exposure to increased cytosolic Ca levels has been shown to prohibit GLUT4 expression in skeletal muscle ${ }^{(54)}$. Furthermore, elevated or sustained cytosolic $\mathrm{Ca}$ levels have been revealed to reduce GLUT4 expression and consequently decrease insulin receptor activity and reduce glucose uptake in adipocytes ${ }^{(4)}$. Because of the pivotal role of insulin in modulating blood glucose ${ }^{(55)}$, abnormalities in circulating Ca levels could potentially impair $\beta$-cell secretory function, glucose intolerance and insulin sensitivity. Thus, it may consequently lead to T2DM development ${ }^{(17)}$. Notably, it has been observed that abnormal intracellular Ca may cause pancreatic $\beta$-cell apoptosis ${ }^{(56,57)}$. Intracellular Ca increases may accompany the activation of endoplasmic reticulum stress and dysfunction of organelles, including mitochondria and the nucleus, which may lead to destruction of pancreatic $\beta$-cells ${ }^{(58)}$. Therefore, future studies investigating such targets might help elucidate mechanisms relevant to the $\mathrm{Ca}$-diabetes association and progression to T2DM.

Several limitations need to be acknowledged when interpreting the findings from this systematic review and meta-analysis. First, most observational studies adopted albumin-adjusted serum Ca as exposure assessment ${ }^{(2,6,9,17,19-21,23,24,37,38)}$, which is prone to errors because of the assumption that $\mathrm{Ca}$ binds to albumin steadily ${ }^{(59,60)}$. In fact, it may neglect other relevant ligands and $\mathrm{Ca}$ fractions ${ }^{(61)}$. Hence, the results of the risk prediction based on measuring albumin-adjusted serum Ca need to be interpreted with caution. Ionised $\mathrm{Ca}$ is considered as the physiologically active form ${ }^{(61)}$ and the 'gold standard' of Ca homeostasis assessment ${ }^{(4,62,63)}$. However, only one available cohort study measured ionised $\mathrm{Ca}$ and reported a null association with incident $\mathrm{T}_{2} \mathrm{DM}^{(10)}$, though it did not appreciably alter the overall association. The association of ionised Ca levels with T2DM risk merits further investigation. Second, serum Ca is highly modulated by some other factors, such as PTH or vitamin D. However, not all primary studies adjusted for these 


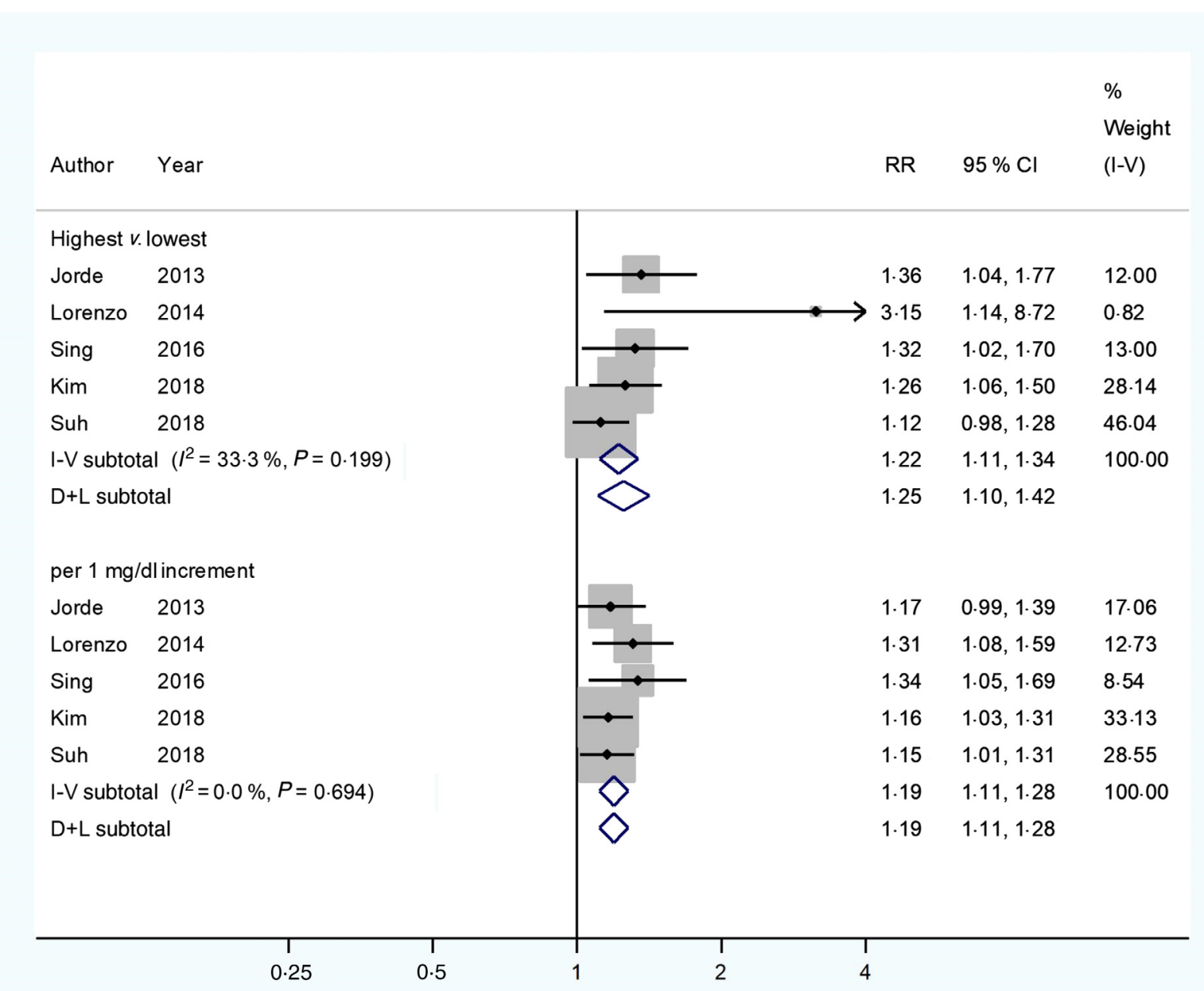

Fig. 3. Multivariable-adjusted relative risks (RR) ( $\bullet$ ) and $95 \%$ confidence intervals ( - ) of type 2 diabetes mellitus (T2DM) in relation to serum total calcium levels. The summary assessments $(\Delta)$ were obtained by adopting a random-effects model. Values are adjusted RR comparing the highest with the lowest category levels or per $1 \mathrm{mg} / \mathrm{dl}$ increase in serum total calcium. The size of the shaded square is proportional to the weight of each study. We requested de novo data from the authors of Kim et al. ${ }^{(22)}$ and Suh et al. ${ }^{(27)}$, respectively.

potential confounding variables. This inherent limitation may somehow affect the combined association. Third, low heterogeneity was evidenced for studies with some serum Ca measurements. The impact should be reduced using a random-effects model in the analyses. Fourth, a potential publication bias could not be completely excluded in some pooled analyses. Nevertheless, the associations were not substantially changed after using the 'trim and fill' method to account for the publication bias. Thus, our conclusion should remain.

In summary, data from this systematic review and metaanalysis provide accumulated evidence supporting the conclusion that circulating $\mathrm{Ca}$ levels are associated with the incidence of T2DM. Further studies are needed to establish the causal inference and elucidate the underlying mechanism of action.

\section{Acknowledgements}

The present study was supported by the National Natural Science Foundation of China (81573140); the US National Institutes of
Health (R01DK116603); the Shanghai Key Laboratory of Pediatric Gastroenterology and Nutrition (14DZ2272400); the Danone Nutrition Research and Education Grant (DIC2017-09) and the Shanghai Municipal Commission of Health and Family Planning (20134196, 2013ZYJB0017).

The authors' contributions were as follows: K. H. conceived the study concept, designed the protocol and supervised the manuscript writing; J. Z. and P. C. X. conducted research, analysed data and wrote the manuscript; J. C. B., J. H. K., D. J. K. and K. F. Y. revised the manuscript. K. H. had primary responsibility for final content. All authors read and approved the final manuscript.

The authors declare that there are no conflicts of interest.

\section{Supplementary material}

For supplementary materials referred to in this article, please visit https://doi.org/10.1017/S0007114519001430 


\section{References}

1. World Health Organization (2014) Global status report on noncommunicable diseases. https://www.who.int/nmh/publications/ ncd-status-report-2014/en/ (accessed January 2019).

2. Seshasai SR, Kaptoge S, Thompson A, et al. (2011) Diabetes mellitus, fasting glucose, and risk of cause-specific death. $N$ Engl J Med 364, 829-841.

3. Jorde R, Schirmer H, Njølstad I, et al. (2013) Serum calcium and the calcium-sensing receptor polymorphism rs17251221 in relation to coronary heart disease, type 2 diabetes, cancer and mortality: the Troms $\varnothing$ Study. Eur J Epidemiol 28, 569-578.

4. Becerra-Tomás N, Estruch R, Bulló M, et al. (2014) Increased serum calcium levels and risk of type 2 diabetes in individuals at high cardiovascular risk. Diabetes Care 37, 3084-3091.

5. American Diabetes Association (2013) Standards of medical care in diabetes. Diabetes Care 36, S11-S66.

6. Rooney MR, Pankow JS, Sibley SD, et al. (2016) Serum calcium and incident type 2 diabetes: the Atherosclerosis Risk in Communities (ARIC) study. Am J Clin Nutr 104, 1023-1029.

7. Sorva A \& Tilvis RS (1990) Low serum ionized to total calcium ratio: association with geriatric diabetes mellitus and with other cardiovascular risk factors. Gerontology 36, 212-216.

8. Peacock M (2010) Calcium metabolism in health and disease. Clin J Am Soc Nephrol 5, S23-S30.

9. Sing CW, Cheng VK, Ho DK, et al. (2016) Serum calcium and incident diabetes: an observational study and meta-analysis. Osteoporos Int 27, 1747-1754.

10. Zaccardi F, Webb DR, Carter P, et al. (2015) Association between direct measurement of active serum calcium and risk of type 2 diabetes mellitus: a prospective study. Nutr Metab Cardiovasc Dis 25, 562-568.

11. Mears D (2004) Regulation of insulin secretion in islets of Langerhans by $\mathrm{Ca}(2+)$ channels. J Membr Biol 200, 57-66.

12. Wollheim CB \& Sharp GW (1981) Regulation of insulin release by calcium. Physiol Rev 61, 914-973.

13. Ojuka EO, Jones TE, Nolte LA, et al. (2002) Regulation of GLUT4 biogenesis in muscle: evidence for involvement of AMPK and $\mathrm{Ca}(2+)$. Am J Physiol Endocrinol Metab 282, E1008-E1013.

14. Begum N, Leitner W, Reusch JE, et al. (1993) GLUT-4 phosphorylation and its intrinsic activity. Mechanism of $\mathrm{Ca}(2+)$-induced inhibition of insulin-stimulated glucose transport. J Biol Chem 268, 3352-3356.

15. American Diabetes Association (2010) Diagnosis and classification of diabetes mellitus. Diabetes Care 33, S62-S69.

16. Procopio M, Magro G, Cesario F, et al. (2002) The oral glucose tolerance test reveals a high frequency of both impaired glucose tolerance and undiagnosed type 2 diabetes mellitus in primary hyperparathyroidism. Diabet Med 19, 958-961.

17. Lorenzo C, Hanley AJ, Rewers MJ, et al. (2014) Calcium and phosphate concentrations and future development of type 2 diabetes: the insulin resistance atherosclerosis study. Diabetologia 57, 1366-1374.

18. Levy J, Stern Z, Gutman A, et al. (1986) Plasma calcium and phosphate levels in an adult noninsulin-dependent diabetic population. Calcif Tissue Int 39, 316-318.

19. Kim MK, Kim G, Jang EH, et al. (2010) Altered calcium homeostasis is correlated with the presence of metabolic syndrome and diabetes in middle-aged and elderly Korean subjects: the Chungju Metabolic Disease Cohort study (CMC study). Atherosclerosis 212, 674-681.

20. Yamaguchi T, Kanazawa I, Takaoka S, et al. (2011) Serum calcium is positively correlated with fasting plasma glucose and insulin resistance, independent of parathyroid hormone, in male patients with type 2 diabetes mellitus. Metabolism 60, 1334-1339.
21. Sun G, Vasdev S, Martin GR, et al. (2005) Altered calcium homeostasis is correlated with abnormalities of fasting serum glucose, insulin resistance, and beta-cell function in the Newfoundland population. Diabetes 54, 3336-3339.

22. Kim KN, Oh SY \& Hong YC (2018) Associations of serum calcium levels and dietary calcium intake with incident type 2 diabetes over 10 years: the Korean Genome and Epidemiology Study (KoGES). Diabetol Metab Syndr 10, 50.

23. Wareham NJ, Byrne CD, Carr C, et al. (1997) Glucose intolerance is associated with altered calcium homeostasis: a possible link between increased serum calcium concentration and cardiovascular disease mortality. Metabolism 46, 1171-1177.

24. Hagström E, Hellman P, Lundgren E, et al. (2007) Serum calcium is independently associated with insulin sensitivity measured with euglycaemic-hyperinsulinaemic clamp in a community-based cohort. Diabetologia 50, 317-324.

25. Shalileh M, Shidfar F, Haghani H, et al. (2010) The influence of calcium supplement on body composition, weight loss and insulin resistance in obese adults receiving low calorie diet. J Res Med Sci 15, 191-201.

26. Mitri J, Dawson-Hughes B, Hu FB, et al. (2011) Effects of vitamin D and calcium supplementation on pancreatic $\beta$ cell function, insulin sensitivity, and glycemia in adults at high risk of diabetes: the Calcium and Vitamin D for Diabetes Mellitus (CaDDM) randomized controlled trial. Am J Clin Nutr 94 , 486-494.

27. Suh S, Bae JC, Jin SM, et al. (2017) Serum calcium changes and risk of type 2 diabetes mellitus in Asian population. Diabetes Res Clin Pract 133, 109-114.

28. Williamson GD, Rennie D, Moher D, et al. (2000) Meta-analysis of observational studies in epidemiology: a proposal for reporting. Meta-analysis of Observational Studies in Epidemiology (MOOSE) group. JAMA 283, 2008-2012.

29. Wells GA, Shea B, O'Connell D, et al. (2019) The NewcastleOttawa Scale (NOS) for assessing the quality of nonrandomised studies in meta-analyses. http://www.ohri.ca/programs/ clinical_epidemiology/oxford.asp (accessed January 2019).

30. Zhao D, Khawaja AT, Jin L, et al. (2018) The directional and non-directional associations of periodontitis with chronic kidney disease: a systematic review and meta-analysis of observational studies. J Periodontal Res 53, 682-704.

31. Elyasi M, Abreu LG, Badri P, et al. (2015) Impact of sense of coherence on oral health behaviors: a systematic review. PLOS ONE 10, e0133918.

32. Ferreira MC, Dias-Pereira AC, Branco-de-Almeida LS, et al. (2017) Impact of periodontal disease on quality of life: a systematic review. J Periodontal Res 52, 651-665.

33. Duval S \& Tweedie R (2000) Trim and fill: a simple funnelplot-based method of testing and adjusting for publication bias in meta-analysis. Biometrics 56, 455-463.

34. Heath H III, Lambert PW, Service FJ, et al. (1979) Calcium homeostasis in diabetes mellitus. J Clin Endocrinol Metab 49, 462-466.

35. McNair P, Fogh-Andersen N, Madsbad S, et al. (1983) Decreased serum concentration of ionized calcium in insulin-dependent human diabetes mellitus. Eur J Clin Invest 13, 267-270.

36. Cho GJ, Shin JH, Yi KW, et al. (2011) Serum calcium level is associated with metabolic syndrome in elderly women. Maturitas 68, 382-386.

37. Shimodaira M, Niwa T, Nakajima K, et al. (2015) The relationship between serum calcium level and early-phase insulin secretion in normoglycemic and pre-diabetic individuals. Exp Clin Endocrinol Diabetes 123, 165-169.

38. Guasch A, Bulló M, Rabassa A, et al. (2012) Plasma vitamin D and parathormone are associated with obesity and atherogenic dyslipidemia: a cross-sectional study. Cardiovasc Diabetol 11, 149. 
39. Pittas AG, Dawson-Hughes B, Li T, et al. (2006) Vitamin D and calcium intake in relation to type 2 diabetes in women. Diabetes Care 29, 650-656.

40. Villegas R, Gao YT, Dai Q, et al. (2009) Dietary calcium and magnesium intakes and the risk of type 2 diabetes: the Shanghai women's health study. Am J Clin Nutr 89, 1059-1067.

41. van Dam RM, Hu FB, Rosenberg L, et al. (2006) Dietary calcium and magnesium, major food sources, and risk of type 2 diabetes in U.S. black women. Diabetes Care 29, 2238-2243.

42. Kirii K, Mizoue T, Iso H, et al. (2009) Calcium, vitamin D and dairy intake in relation to type 2 diabetes risk in a Japanese cohort. Diabetologia 52, 2542-2550.

43. Dong JY \& Qin LQ (2012) Dietary calcium intake and risk of type 2 diabetes: possible confounding by magnesium. Eur $J$ Clin Nutr 66, 408-410.

44. Reis JP, Selvin E, Pankow JS, et al. (2016) Parathyroid hormone is associated with incident diabetes in white, but not black adults: the Atherosclerosis Risk in Communities (ARIC) Study. Diabetes Metab 42, 162-169.

45. Song Y, Wang L, Pittas AG, et al. (2013) Blood 25-hydroxy vitamin D levels and incident type 2 diabetes: a meta-analysis of prospective studies. Diabetes Care 36, 1422-1428.

46. Gray E, Muller D, Squires PE, et al. (2006) Activation of the extracellular calcium-sensing receptor initiates insulin secretion from human islets of Langerhans: involvement of protein kinases. J Endocrinol 190, 703-710.

47. Jones PM, Kitsou-Mylona I, Gray E, et al. (2007) Expression and function of the extracellular calcium-sensing receptor in pancreatic beta-cells. Arch Physiol Biochem 113, 98-103.

48. Henquin JC (2000) Triggering and amplifying pathways of regulation of insulin secretion by glucose. Diabetes $\mathbf{4 9}$, $1751-1760$.

49. Jing X, Li DQ, Olofsson CS, et al. (2005) CaV2.3 calcium channels control second-phase insulin release. J Clin Invest $\mathbf{1 1 5}$, 146-154.

50. Pittas AG, Lau J, Hu FB, et al. (2007) The role of vitamin D and calcium in type 2 diabetes. A systematic review and metaanalysis. J Clin Endocrinol Metab 92, 2017-2029.

51. Ko SH, Lee GS \& Vo TT (2009) Dietary calcium and 1, 25-dihydroxyvitamin D3 regulate transcription of calcium transporter genes in calbindin-D9k knockout mice. I Reprod Dev 55, 137-142.

52. Draznin B, Lewis D, Houlder N, et al. (1989) Mechanism of insulin resistance induced by sustained levels of cytosolic free calcium in rat adipocytes. Endocrinology 125, 2341-2349.

53. Draznin B, Sussman KE, Eckel RH, et al. (1988) Possible role of cytosolic free calcium concentrations in mediating insulin resistance of obesity and hyperinsulinemia. J Clin Invest $\mathbf{8 2}$, 1848-1852.

54. Park S, Scheffler TL, Gunawan AM, et al. (2009) Chronic elevated calcium blocks AMPK-induced GLUT-4 expression in skeletal muscle. Am J Physiol Cell Physiol 296, C106-C115.

55. Khan AH \& Pessin JE (2002) Insulin regulation of glucose uptake: a complex interplay of intracellular signalling pathways. Diabetologia 45, 1475-1483.

56. Chandra J, Zhivotovsky B, Zaitsev S, et al. (2001) Role of apoptosis in pancreatic beta-cell death in diabetes. Diabetes 50, S44-S47.

57. Wang L, Bhattacharjee A, Zuo Z, et al. (1999) A low voltage-activated $\mathrm{Ca}^{2+}$ current mediates cytokine-induced pancreatic betacell death. Endocrinology 140, 1200-1204.

58. Ramadan JW, Steiner SR, O'Neill CM, et al. (2011) The central role of calcium in the effects of cytokines on beta-cell function: implications for type 1 and type 2 diabetes. Cell Calcium 50, 481-490.

59. Calvi LM \& Bushinsky DA (2008) When is it appropriate to order an ionized calcium? J Am Soc Nephrol 19, 1257-1260.

60. Zhao G, Ford ES \& Li C (2010) Associations of serum concentrations of 25-hydroxyvitamin D and parathyroid hormone with surrogate markers of insulin resistance among U.S. adults without physician-diagnosed diabetes: NHANES, 2003-2006. Diabetes Care 33, 344-347.

61. Guynn RW, Veloso D \& Veech RL (1972) Enzymic determination of inorganic phosphate in the presence of creatine phosphate. Anal Biochem 45, 277-285.

62. Baird GS (2011) Ionized calcium. Clin Chim Acta 412, 696-701.

63. Bushinsky DA \& Monk RD (1998) Electrolyte quintet: calcium. Lancet 352, 306-311. 